\title{
An Approach for Teaching English Language Grammar To Arab Young Learners
}

\author{
Ebtesam A. O. BaSaeed \\ (Department of Curriculum and Instruction, King Saud University, Saudi Arabia)
}

\begin{abstract}
Because English and Arabic are not from the same linguistic family, they display huge grammatical differences. Indeed, some elements in English grammar are not even found in Arabic. Therefore, Arab students face difficulties understanding these elements, particularly the usage and function of the verbs be, do, and have and applying the present perfect tense correctly. This paper aims to help Arab young learners overcome these difficulties by designing a new method to facilitate and accelerate learning English grammar. This method depends on teaching each verb as a main part of a unit rather than as a small part of a grammar rule that is covered at the end of a unit, which may not serve the unit's topic. In this way, students can learn the conjugation of the verb as well as how to form questions, make negatives, and, most importantly, apply it properly in real life. Further, the present perfect tense is connected with the present, present progressive, and present perfect progressive in one unit or one chapter in order for learners to better imagine the sequence of time.

Keywords: Arab learners, English grammar, Foreign language, Language acquisition, Language and culture.
\end{abstract}

\section{Introduction}

It is clear from various research that native language has a positive or negative effect on learning a target language, especially at the beginning stages of acquiring the latter [12]. Learning a new language seems to rely on the grammar of the native language to some extent [12]. Individuals tend to transfer the forms and meanings and the distribution of forms and meanings of their native language and culture to the foreign language and culture [15]. Arab EFL learners commit inter-lingual errors more than intra-lingual ones [3]. Moreover, the principal barrier to the second language system is the interference of the first language system with the second language system. It is considered that interference is the result of CA and it causes errors [6]. In addition, interference (negative transfer) is the negative influence of the mother language (L1) on the performance of the target English language learner [15].

This effect depends mainly on the similarities between languages, such as those between English and French or Arabic and Persian. However, because some languages show major differences, such as English and Korean or English and Arabic, English should not be taught using a globally accepted sequence of restricted rules. Instead, teaching approaches should be more flexible and practical depending on the nature of the learner's first language as well as his or her culture and background [10].

Arab learners experience difficulties when trying to understand and comprehend the correct function and usage of the verbs be, have, and $d o$, since there are no counterparts in Arabic [8]. As these verbs greatly influence English grammar, they are a challenge for most Arab learners. Further, the present perfect tense is completely new for Arab learners and this can become troublesome since they have no equivalent in Arabic [14].

Therefore, this paper suggests a novel approach to teaching the perfect tense and the verbs $b e, d o$, and have that is completely different from the traditional method. It is hoped that this method will be able to help young Arab learners understand and diagnose the perfect tense and copular verbs.

\subsection{Methodology}

\subsubsection{Problem of the Study}

The present paper discusses the difficulties that young Arab learners face when learning the perfect tense and when diagnosing the functions and usage of the verbs be, have, and do.

\subsubsection{Objectives of the Study}

- Facilitate and accelerate teaching English grammar to young Arab learners; and

- Develop new techniques and methods for teaching English grammar to young Arab learners. 


\subsubsection{Question of the Study}

- What difficulties are faced by young Arab learners when learning English grammar?

- What teaching techniques and methods can overcome these difficulties?

\subsubsection{Significance of the Study}

Huge numbers of people speak Arabic. This approach will impact a large sub-population of EFL Arabic students, they are frequent students in EFL programs. Increasing contact between the Arabic-speaking world and the English-speaking world creating higher demand for English instruction that meets their needs. Therefore, this approach is to formulate helpful techniques and procedures for young Arab learners to facilitate learning the perfect tense and copula verbs.

\section{Literature Review}

Although teaching grammar is a critical issue, knowing how, when, and what to teach can be complicated, especially because there is a lack of consensus in the literature. Therefore, the question is not whether grammar should be taught to students, but rather how it should be taught. Individuals tend to transfer the forms and meanings and the distribution of these forms and meanings of their native languages to the foreign language [15]. Researchers such as Mohammed and Abisamra pointed out that Arab English language learners make serious inter-lingual errors because they depend heavily on their native language [17 \& 1].

In many parts of the world, teaching English grammar has changed from a traditional approach (i.e., teaching formal grammar rules) to a more communicative approach (i.e., how to use grammar meaningfully in context) [13]. Communicative drills encourage students to connect form, meaning, and use because many correct responses are possible.

According to Gardner, grammar can be taught in many ways; there is no 'best' way that suits all grammar rules. In a study of the state of foreign language teaching that began in 1923 [13], Franz proved that no single method could guarantee successful results. Students find grammar most interesting when they apply it to authentic, clear, and simple texts, study situations and topics that occur in real life and use all the language skills (listening, speaking, reading, and writing). This paper suggests a way of teaching the verb be that may make learning easier for young Arab learners. This verb should be presented in a unit that explains its conjugation, functions, and usage [11].

\section{The Verb Be}

The verb be is the first verb students learn in their English studies; it is one of the basic elements of a sentence that some Arab students have problems conjugating. This is because Arabic sentences, unlike English ones, can occur without verbs. In addition, there is no equivalent verb in Arabic when the verb to be is used as the main verb in the present tense in a sentence.

Fortunately, there are a number of ways, such as figures, short stories with pictures, and simple conversation of teaching the many forms of the verb $b e$. the researcher uses figures to illustrate and simplify the conjugation and functions of the verb be.

Moreover, games help students easily internalize the function and usage of the verb be through meaningful play in the language learning classroom. Games keep many student motivation high and help with natural learning. Following are some points of views from famous figures in this field. Just like songs and rhymes, games also provide wonderful atmosphere in the children's language class. It is widely documented that English language games improve learning, and with children, they are one of the most effective classroom tools [4]. Playing a game has a purpose and an outcome. In order to play, students have to say things. Therefore, they have a reason to communicate and this makes them want to know and learn more. In addition to this, games stimulate and motivate children to a new level. They know that if they do not pay attention, they will not be able to play the game well and they will let their team down so they make more effort to join in and learn as much as possible [22]

It can be said that English language games actually give students a reason to communicate, and a context for speaking practice [4]. "Enjoyment and fun as part of the learning process are important when learning new tools since the learner is relaxed and motivated and therefore more willing to learn." ... "The role that fun plays with regard to intrinsic motivation in education is twofold. First, intrinsic motivation promotes the desire for recurrence of the experience...Secondly, fun can motivate learners to engage themselves in activities with which they have little or no previous experience." [5]. So fun in the learning process creates relaxation and motivation. Relaxation enables learners to take things in more easily; motivation enables them to put forth effort without resentment. Given this, it certainly makes sense that fun and learning should go hand in hand [18]. Grammar is one reason why English is a difficult language for some learners. Thus, grammar learning should be fun and meaningful, also making it memorable [16]. 
In Fig. 1, the researcher provides an overview of the conjugations of the verb be. The researcher suggests using the human body because it is easy for learners to internalize. The head always means the main part of the body, which corresponds with the verb be. Hands are the part of the body that are used most in daily life, so these represent the present and past tense. The deflated balloons in the right hand of the figure represent the past tense, whereas those in the left hand stand for the present tense. Moreover, each balloon in the left hand matches with the correct conjugation in the balloons in the right hand by using the same color to avoid confusion. Legs, which are used less than hands, are represented by been and being, which are used less in daily life (i.e., more complicated sentences) .

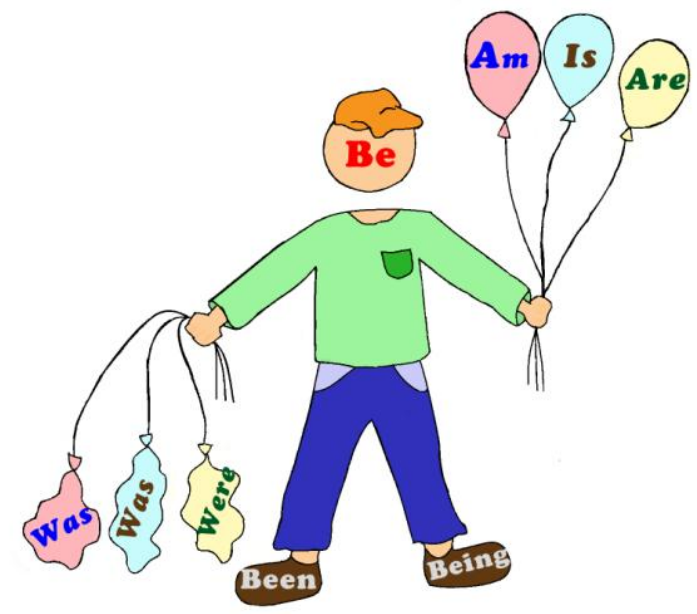

Figure 1. Be's family.

The inspiration for this idea came from methods common in geography and science classes. In a geography lesson, the teacher shows students a map of a target country and then explains and identifies, step-bystep and perhaps over more than one lesson, the states of the country, its borders, its most important cities, and its topography. Moreover, when the teacher wants to give more details about, for example, topography, he or she uses a different map to help students focus on the new information. The same thing happens in a basic science class: the teacher shows students the skeleton of a human body to explain its main parts. Therefore, this can be applied to identifying the whole family of the verb be in one simple figure. Moreover, using such an illustration clarifies the whole picture of the verb's family to students and makes it easy to imagine. This is similar to a jigsaw: if the whole picture is clear in a student's mind, then it is easy for him or her to put the right pieces in the right places.

Fig. 2 is designed to simplify and clarify the functions of the verb be. The figure shows that it functions either as a full verb or as an auxiliary verb in a sentence.

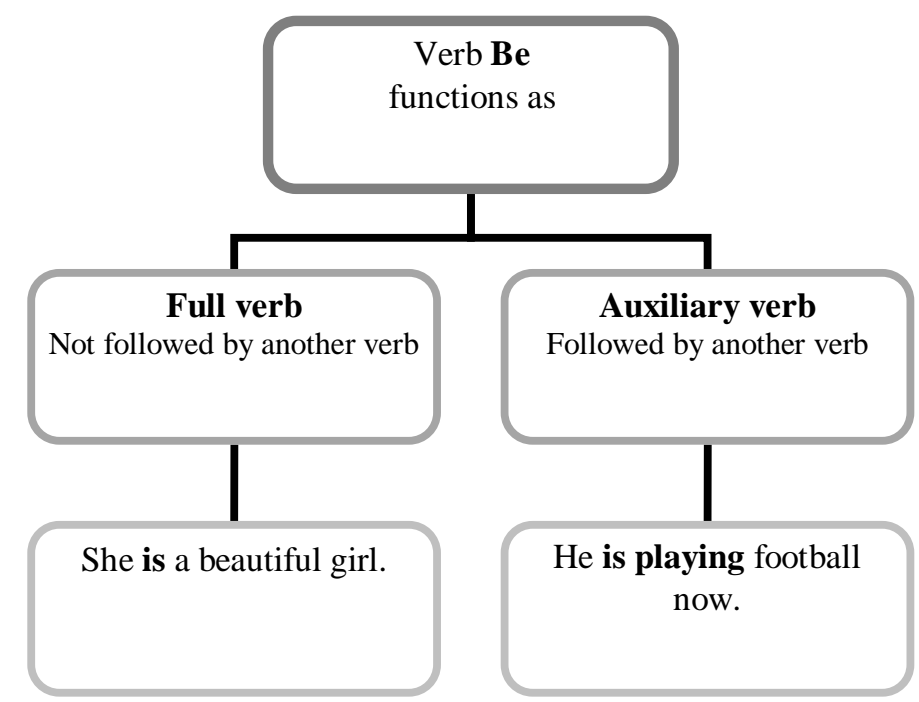

Figure 2. Functions of the verb $b e$. 
Tables 1 and 2 specify the function of the verb $b e$ when it is associated with a specific pronoun or a specific tense.

\begin{tabular}{|l|l|l|l|}
\hline \multicolumn{4}{|c|}{ Table . Illustration of be as a full verb } \\
\hline & Present & Past & Future \\
\hline I & I am a teacher. & I was a student. & I will be a teacher. \\
\hline she/he/it & She is beautiful. & She was ugly. & She will be a doctor. \\
\hline we/they/you & They are doctors. & They were students. & We will be doctors. \\
\hline
\end{tabular}

\begin{tabular}{|c|c|c|c|}
\hline \multicolumn{4}{|c|}{ Table 2. Illustration of be as an auxiliary verb } \\
\hline & Present progressive & Past progressive & Perfect form \\
\hline I & I am reading a book. & I was reading a book. & I have been working. \\
\hline he/she/it & He is playing football. & $\begin{array}{c}\text { He was playing } \\
\text { football. }\end{array}$ & $\begin{array}{c}\text { He has/had been playing } \\
\text { football. }\end{array}$ \\
\hline you/we/they & They are watching TV. & $\begin{array}{c}\text { They were watching } \\
\text { TV. }\end{array}$ & $\begin{array}{c}\text { They have/had been studying. } \\
\end{array}$
\end{tabular}

Figs. 3-1, 2, and 3 explain the usage of each pronoun as an individual grammatical entity when it is associated with the verb be. This helps students internalize and deal with each pronoun separately when it is in a different tense.

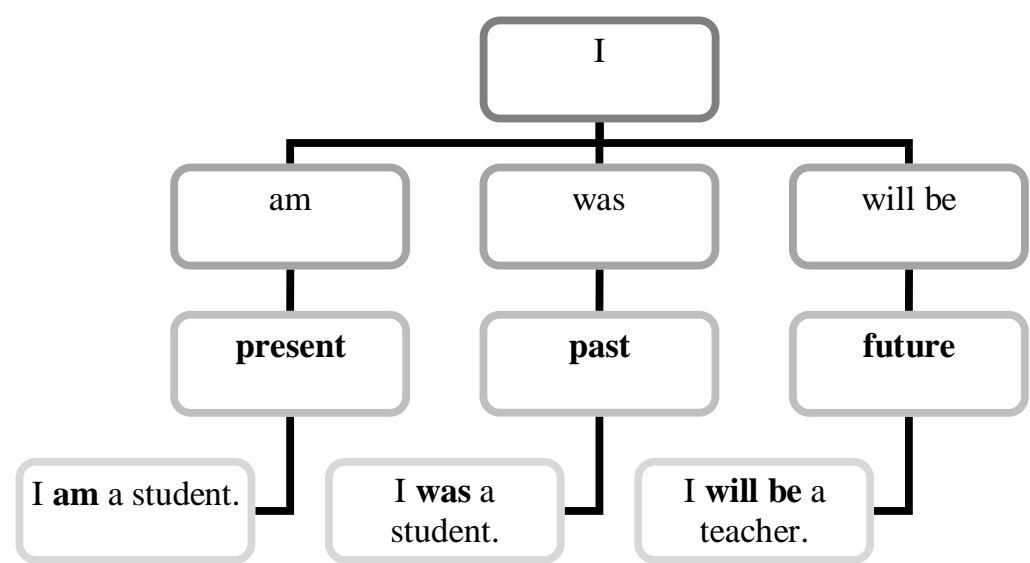

Figure 3-1. Pronoun-verb agreement.

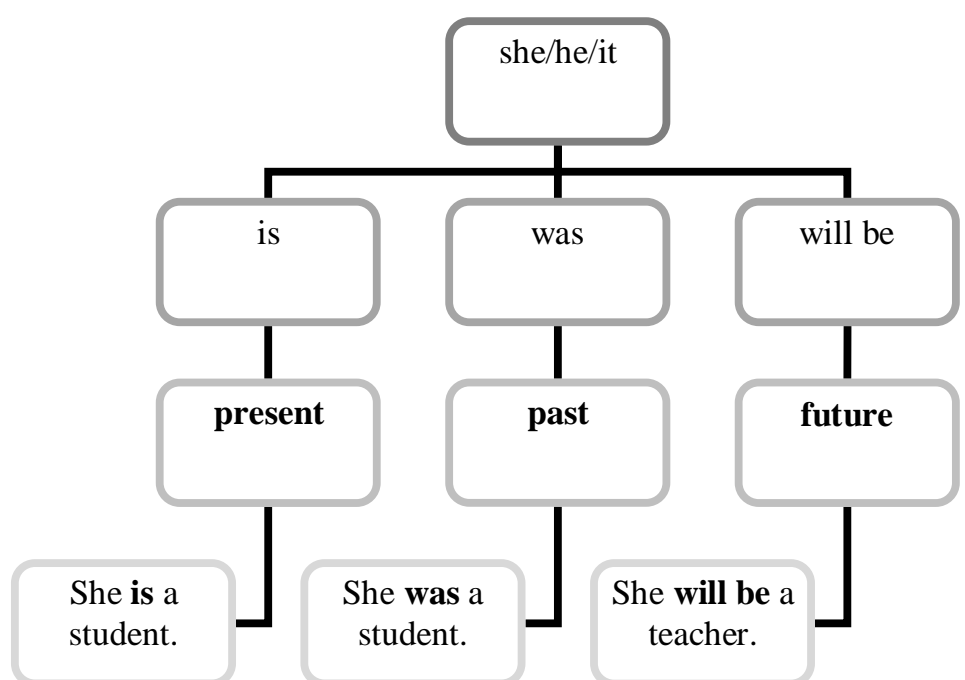

Figure 3-2. Pronoun-verb agreement. 


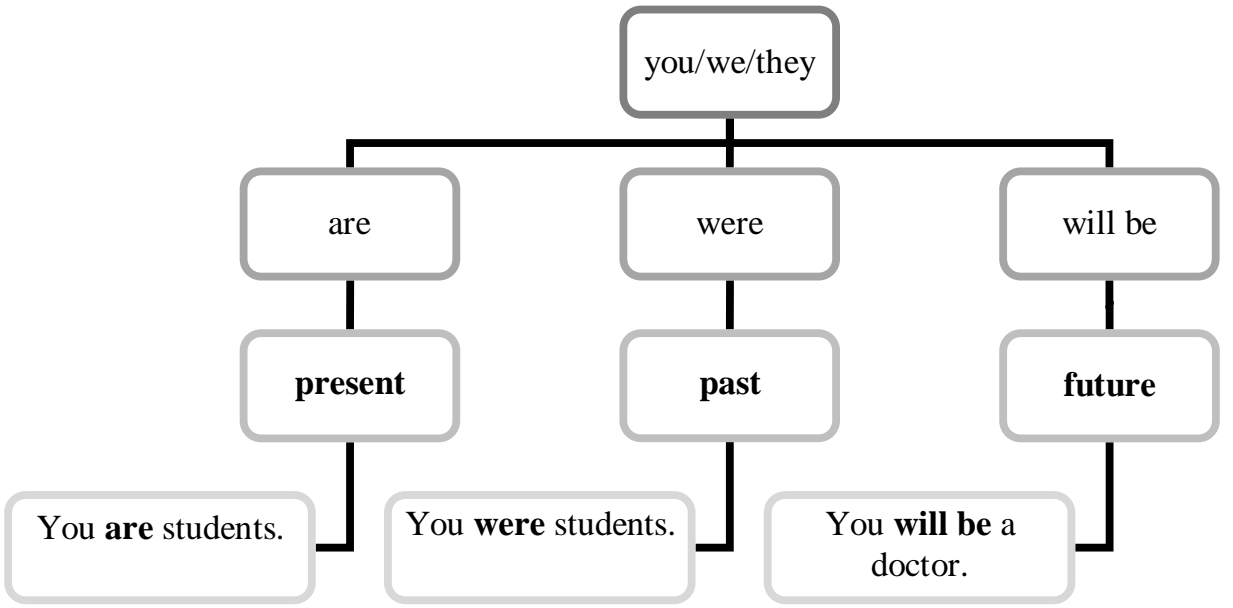

Figure 3-3. Pronoun-verb agreement.

\section{The Verb Do}

The verb $d o$ is a common verb in English that young Arab learners face difficulty understanding in terms of its function and usage. The verb do is classified as an action verb that describes what the subject does or what is done to him or her. Moreover, it can be used as an auxiliary and a main verb. It is necessary for the grammatical structure of a sentence. Figures and tables to explain and clarify the usage of the verb do.

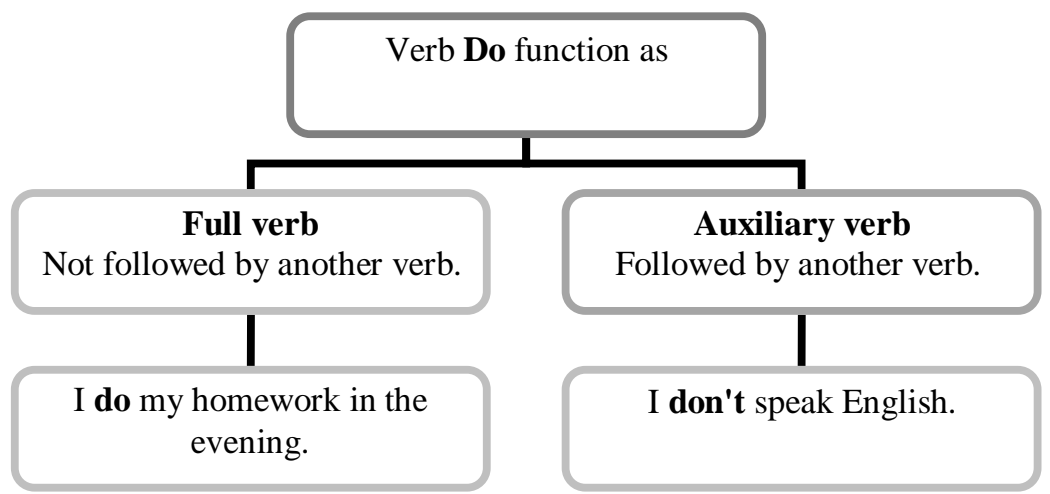

Figure 4. Functions of the verb $d o$.

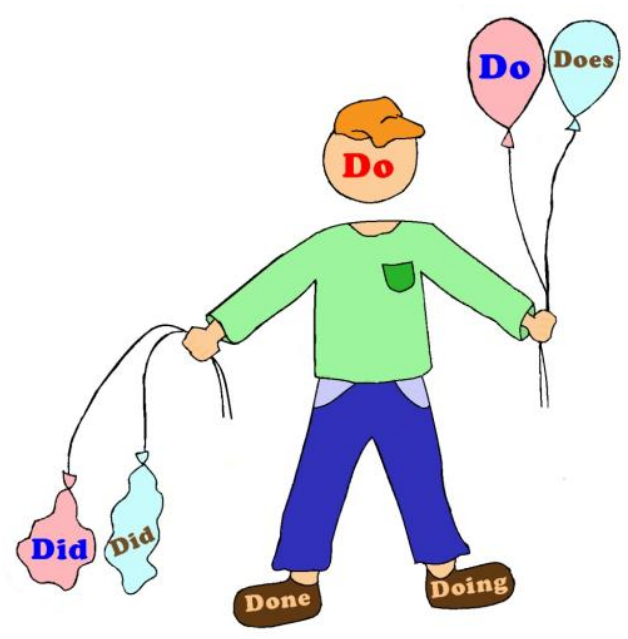

Figure 5. Do's family. 


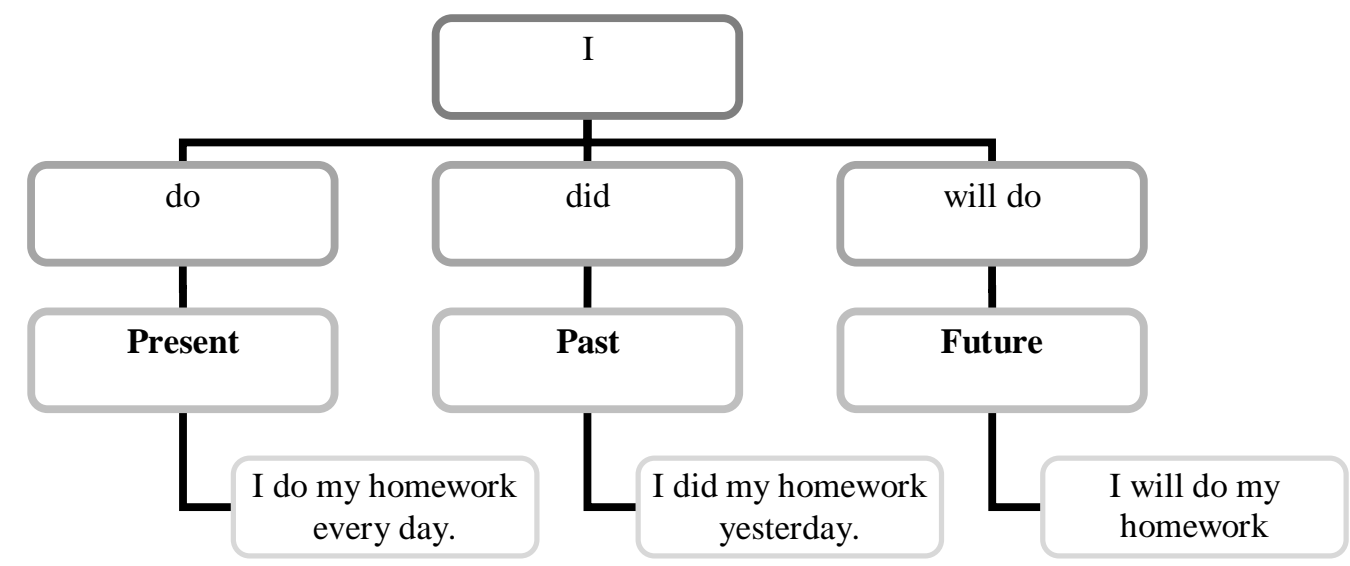

Figure 6. Pronoun-verb agreement.

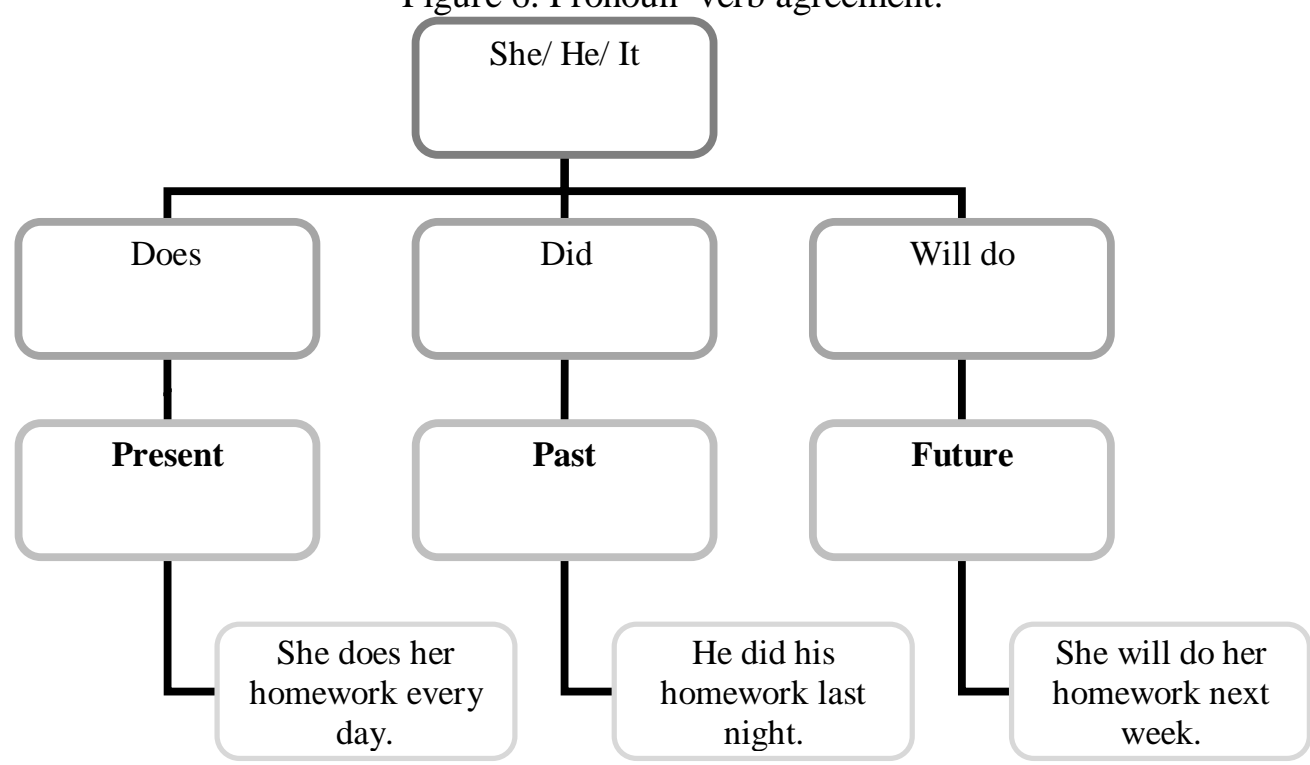

Figure 7. Pronoun-verb agreement.

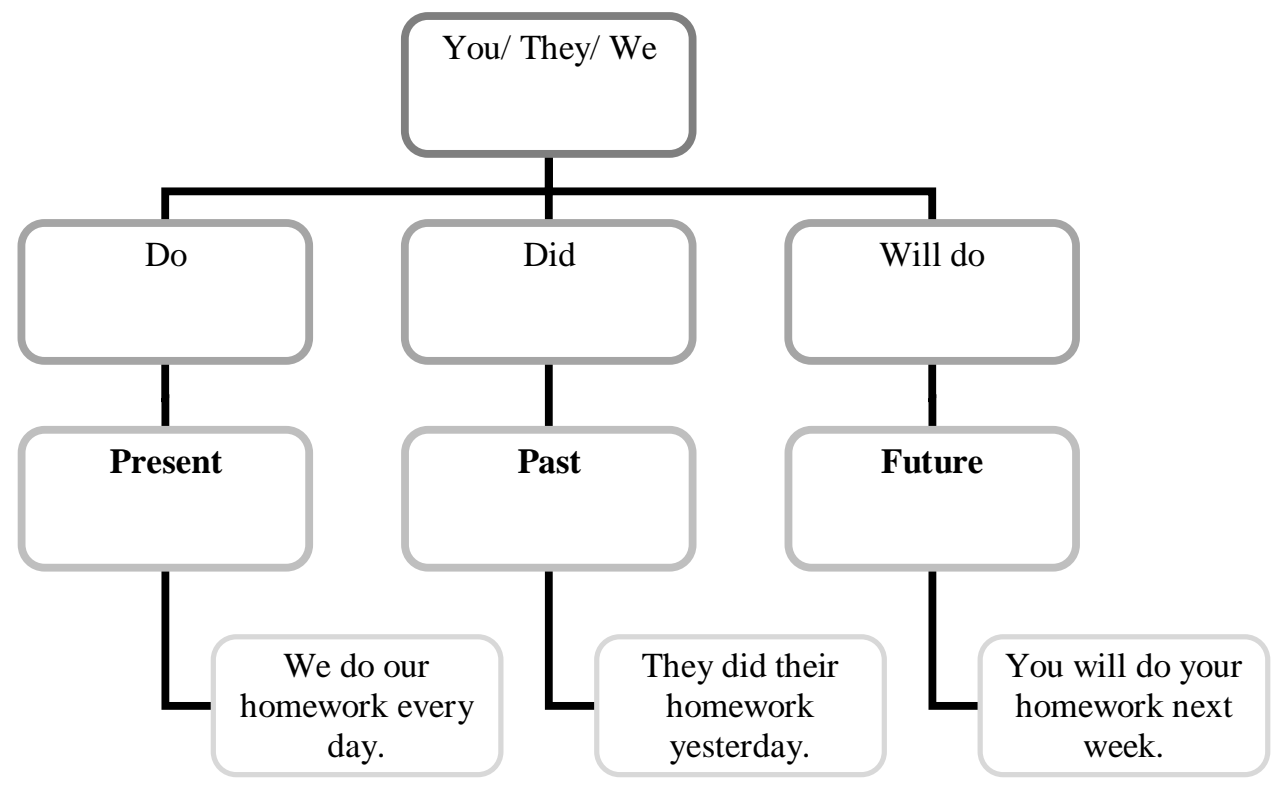

Figure 8. Pronoun-verb agreement. 
An Approach for Teaching English Language Grammar to Arab Young Learners

\begin{tabular}{|c|c|c|c|}
\hline & Present & Past & Future \\
\hline $\mathrm{I}$ & $\begin{array}{l}\text { I usually do my } \\
\text { homework in the } \\
\text { evening. }\end{array}$ & $\begin{array}{l}\text { I did my homework } \\
\text { yesterday evening. }\end{array}$ & $\begin{array}{l}\text { I will do my homework } \\
\text { next week. }\end{array}$ \\
\hline she/he/it & $\begin{array}{l}\text { She sometimes does her } \\
\text { homework in the } \\
\text { evening. }\end{array}$ & $\begin{array}{l}\text { He did his homework } \\
\text { yesterday. }\end{array}$ & $\begin{array}{l}\text { She will do her homework } \\
\text { tomorrow. }\end{array}$ \\
\hline we/they/you & $\begin{array}{l}\text { We normally do our } \\
\text { homework in the } \\
\text { evening. }\end{array}$ & $\begin{array}{l}\text { They did their } \\
\text { homework last Friday. }\end{array}$ & $\begin{array}{l}\text { You will do your } \\
\text { homework next Monday. }\end{array}$ \\
\hline
\end{tabular}

\begin{tabular}{|l|l|l|l|}
\hline \multicolumn{3}{|c|}{ Table 4. Illustration of do as an auxiliary verb } \\
\hline & Present & Past & Question \\
\hline & I do not play football. & $\begin{array}{l}\text { I did not play } \\
\text { football last night. }\end{array}$ & $\begin{array}{l}\text { Do you play football? } \\
\text { Did you play football last night? }\end{array}$ \\
\hline he/she/it & $\begin{array}{l}\text { He does not play } \\
\text { football. }\end{array}$ & $\begin{array}{l}\text { He did not play } \\
\text { football last night. }\end{array}$ & $\begin{array}{l}\text { Does he play football? } \\
\text { Did he play football last night? }\end{array}$ \\
\hline you/we/they & $\begin{array}{l}\text { They do not play } \\
\text { football daily. }\end{array}$ & $\begin{array}{l}\text { They did not play } \\
\text { football yesterday. }\end{array}$ & $\begin{array}{l}\text { Do they play football daily? } \\
\text { Did they play football } \\
\text { yesterday? }\end{array}$ \\
\hline
\end{tabular}

Moreover, supported games that help students distinguish between the verb do and the verb make. Many young Arab students confuse using them in the correct sentence because they have the same meaning in Arabic.

\section{The Verb Have}

Have is one of the most common verbs in the English language; however, some young Arab students confuse the function of this verb since it functions in various ways. As a main verb, to have implies possession (I have a car) or expresses an action (I have a shower every day). Moreover, to have is used as an auxiliary verb to help other verbs create the perfect tense. The verb have is much easier than be and do for many young students to grasp.

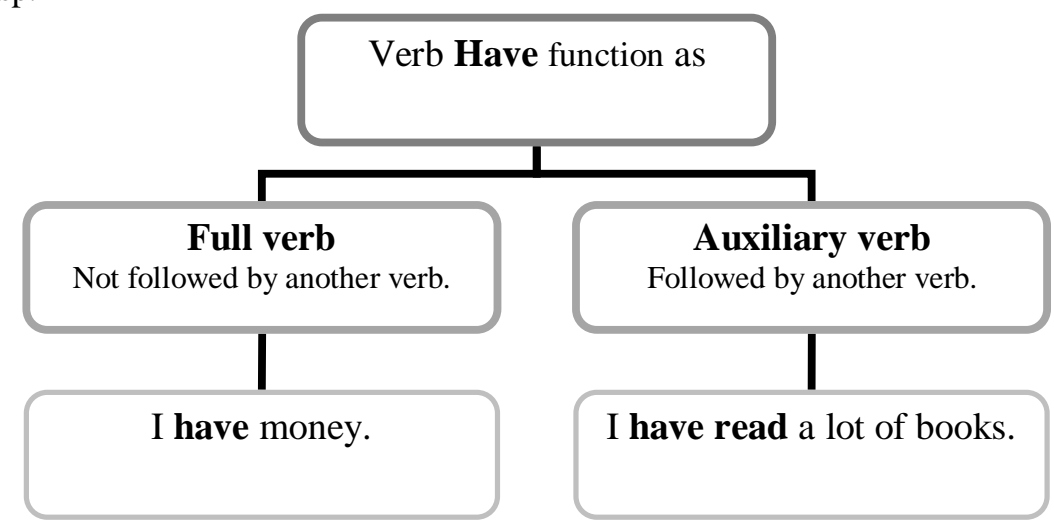

Figure 9. Functions of the verb have. 


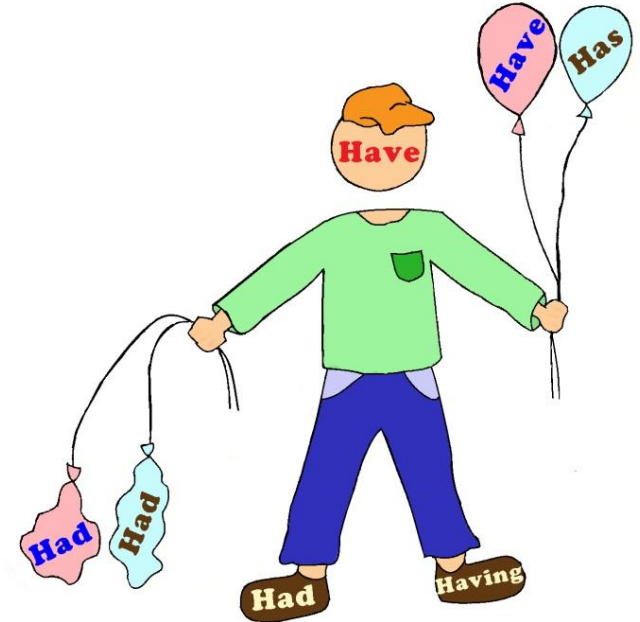

Figure 10. Have's family.

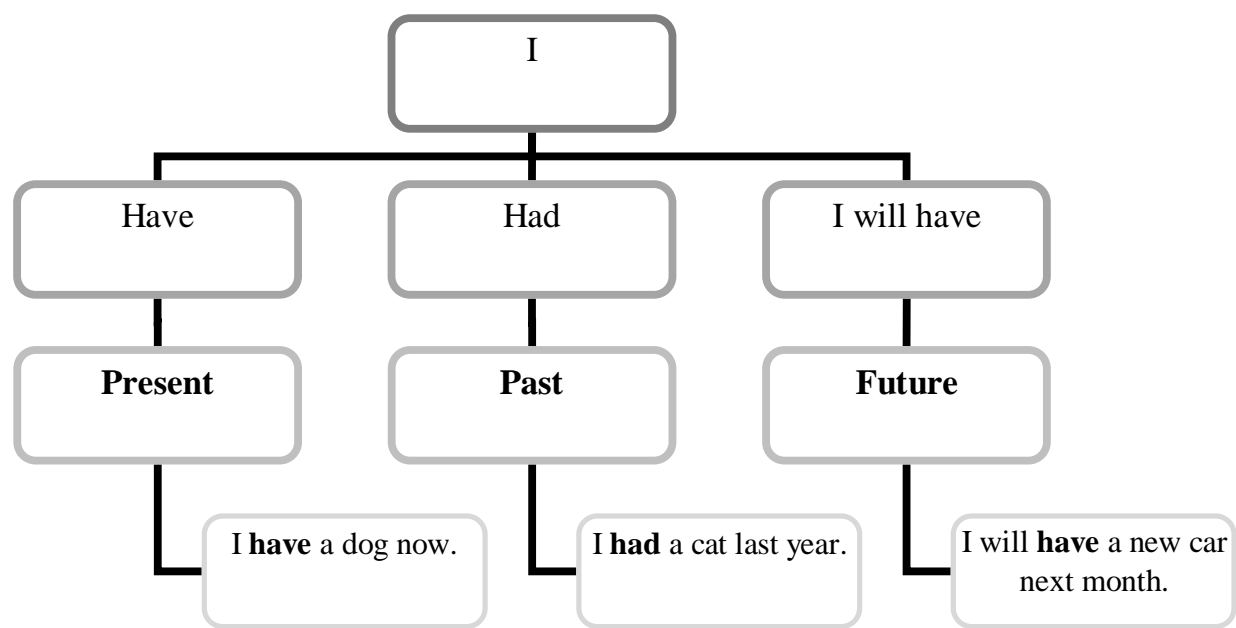

Figure 11. Pronoun-verb agreement

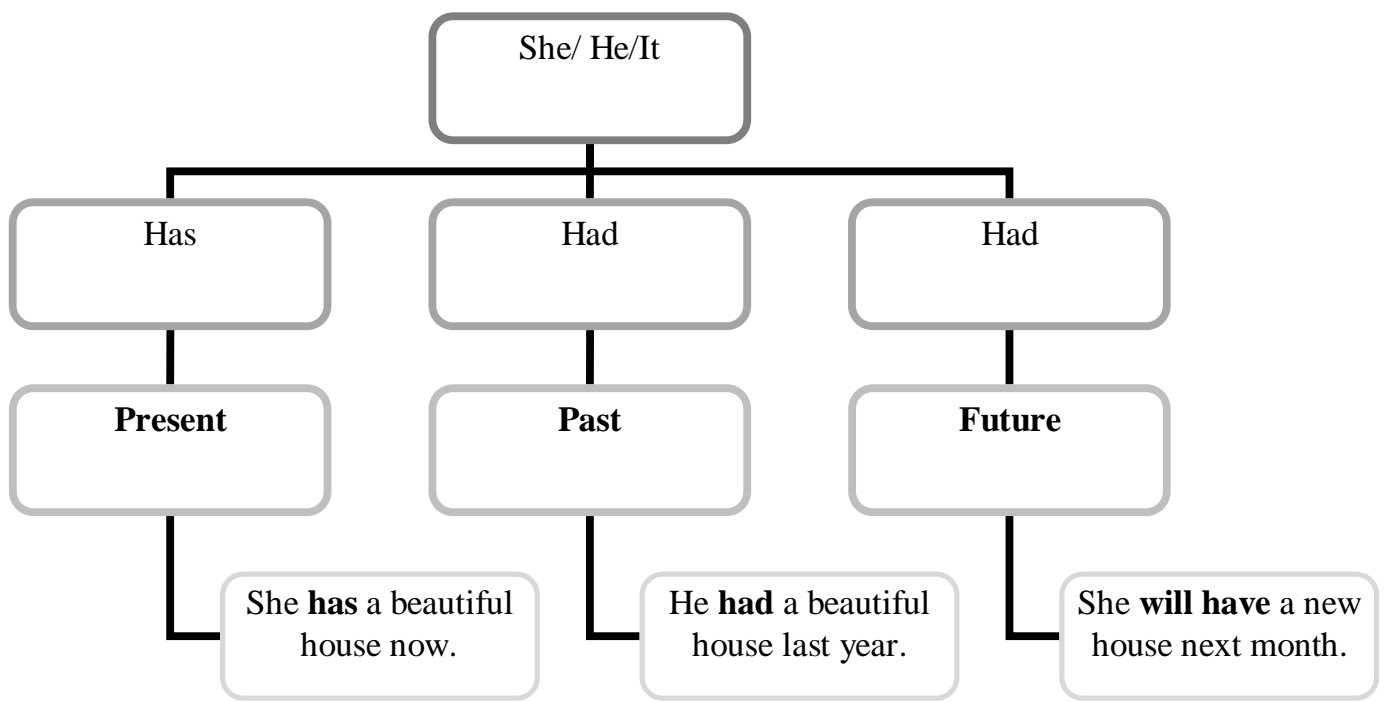

Figure 12. Pronoun-verb agreement 


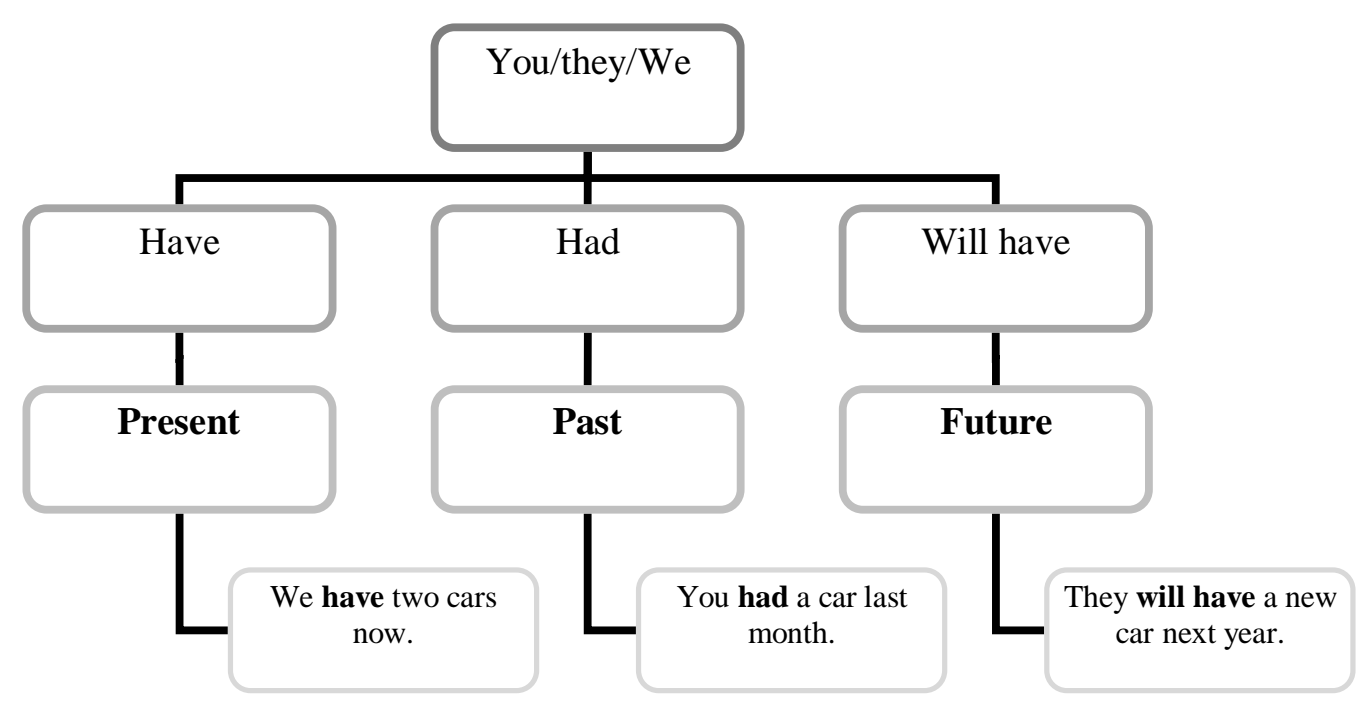

Figure 13. Pronoun-verb agreement

\begin{tabular}{|l|l|l|}
\hline \multicolumn{2}{|c|}{ Table 5. Illustration of have as a full verb } \\
\hline \multicolumn{2}{|c|}{ Forms of the verb have when it functions as a full verb } \\
\hline & Present & Past \\
\hline I & I have a beautiful house. & I had a beautiful house. \\
\hline she/he/it & She has a modern car. & He had a modern car. \\
\hline we/they/you & $\begin{array}{l}\text { We usually have a lot of } \\
\text { homework. }\end{array}$ & $\begin{array}{l}\text { They had a lot of homework last } \\
\text { week. }\end{array}$ \\
\hline
\end{tabular}

\begin{tabular}{|l|l|l|}
\hline \multicolumn{3}{|c|}{ Table 6. Illustration of have as an auxiliary verb } \\
\hline \multicolumn{2}{|c|}{ Forms of the verb have when it functions as an auxiliary verb } \\
\hline & Present perfect & Past perfect \\
\hline I & $\begin{array}{l}\text { I have read this book many } \\
\text { times. }\end{array}$ & I had read this book once. \\
\hline she/he/it & $\begin{array}{l}\text { He has played football for } \\
\text { a long time. }\end{array}$ & He had played football for one week. \\
\hline we/they/you & $\begin{array}{l}\text { We have had four tests so } \\
\text { far. }\end{array}$ & $\begin{array}{l}\text { After the students had left, the school } \\
\text { closed. }\end{array}$ \\
\hline
\end{tabular}

Games that require students to use the verb have in math problems. In these games, students learn that the English language is flexible and can be used and applied in any situation and for any subject.

\section{The Perfect Tense}

Arab students struggle to understand the perfect tense since it has no counterpart in Arabic[19]. This tense is usually confused with the simple past. The present perfect describes a past happening that is related in some way to the present [7]. The differences between the present perfect and past simple are complicated and difficult to analyze, while the rules given in grammar are not always clear and accurate [20].

The present perfect is a kind of present tense. When we say that something has happened, or has been happening, we are generally thinking about the present as well as the past. Hence, we can say that this tense is a mixture of the present and past - it always implies a strong connection with the present [7]. The student who comes in contact with a foreign language will find some features of it quite easy and others extremely difficult. Those elements that are similar to his language will be simple for student, and those elements that are different will be difficult [15]. The first grammatical problem that most of the students of the present study seemed to run into is that of tense. The difficulty becomes more serious when the students have to deal with complex tenses like the present perfect [14]. Saudi learners face problems in the learning of almost all aspects of the target language's grammar [2].

Therefore, young Arab students should be taught present, present progressive, present perfect, and present perfect progressive connected together in one unit or one chapter so learners can better imagine the 
sequence of time in order to overcome this problem. Moreover, the focus should be more on our attitude and the result of the event.

These pictures illustrate the usage of the four tenses in a simple way. The presented pictures are selfexplanatory, which clarifies the use of grammar for students. Therefore, using pictures simplifies the focus, which should be on the result of the action rather than on the action itself.

He loves running.

\section{Conclusion}

Teaching grammar is serious, knowing how, when, and what to teach has been a controversial issue among scholars in the field. Following are some points of views from famous figures in this field. Grammar teaching involves any instructional technique that draws learners' attention to some specific grammatical form in such a way that it helps them either to understand it meta-linguistically and/or process it in comprehension and/or production so that they can internalize it [9]. As VanPatten, Williams, and Rott emphasize, establishing connections between form and meaning is a fundamental aspect of language acquisition [21]. N. Ellis has suggested that learning necessarily commences with an explicit representation of linguistic forms, which are then developed through implicit learning. He suggests that teaching grammar early is valuable because it provides a basis for the real learning that follows [9].

Native language clearly affects learning the target language, especially at the beginning stages of acquiring it, while students rely on the grammar of their native languages to overcome any difficulties. However, this method does not always work because English and Arabic have huge differences in grammar.

Many young Arab students encounter difficulties with the function and usage of the verbs $b e$, do, and have because there are no equivalent verbs in Arabic. These verbs are crucial to understand, as they play a great role in forming tenses, questions, and negatives in English grammar. Comprehending these verbs is thus essential for accuracy and fluency in speaking and writing. In addition, the present perfect tense is another troublesome area for many young Arab students because it expresses past events with reference to the present. Many young Arab students become confused when choosing between the past and the present perfect, since the latter has no counterpart in Arabic. 
This study aimed to help young Arab students use the verbs $b e$, do, and have as well as the present perfect accurately and meaningfully. In other words, the researcher's technique aims to teach these rules as a skill set rather than as rules to be memorized based on form, meaning, and usage and relate them to students' communicative needs and experiences in real-life situations.

To clarify the function and usage of the verbs $b e$, do, and have, the researcher uses the human body, which is easy for young learners to recognize. Head always means the main part of the body, which corresponds with the main verb $b e$. Hands are the part of the body that are used most in daily life, so these represent the present and past tense. The deflated balloons in the right hand of the figure in Figure 1 represent the past tense, whereas those in the left hand stand for the present tense. Moreover, each balloon in the left hand matches with the right conjugation in the balloons in the right hand by using the same color to avoid confusion. Legs, which are used less than hands, are represented by been and being, which are used less in daily life (i.e., more complicated sentences).

Therefore, this can be applied to identifying the whole family of any verb in one simple figure. Moreover, using such an illustration clarifies the whole picture of the verb's family to students and makes it easy to imagine. This is similar to a jigsaw: if the whole picture is clear in a student's mind, then it is easy for him or her to put the right pieces in the right places.

Moreover, figure 2 are designed to illustrate and clarify the functions of the three verbs. They show that these particular verbs function either as a full verb or as an auxiliary verb in a sentence. Additionally, the presented tables provide more details about the function of these verbs when they are associated with a specific pronoun or a specific tense.

As for the present perfect, to enhance comprehension all tenses are linked together so learners can better imagine the sequence of time. This method can also be applied to the past and future tenses.

\section{References}

[1] Abisamra, N. An analysis of errors in Arabic speakers' English writings. American University of Beirut. 2003, Retrieved from http://abisamra03.tripod.com/nada/languageacq-erroranalysis.html.

[2] Alam Khan, Intakhab. Role of Applied Linguistics in the Teaching of English in Saudi Arabia. International Journal of English Linguistics, Vol. 1, No. 1; March, 2011.

[3] Al-Jarf, Reima Sado. Analysis of Grammatical Agreement Errors in L1/L2 translation. International Review of Applied Linguistics, 38, 2000, pp. 1-15.

[4] Ara, Shaheen. Use of Songs, Rhymes and Games in Teaching English to Young Learners in Bangladesh. The Dhaka University Journal of Linguistics Vol. 2 No.3, February, 2009.

[5] Bisson, Christian and John Luckner. Fun in Learning: The Pedagogical Role of Fun in Adventure Education. Journal of Experimental Education, Vol. 9, No. 2, 1996, pp 109-110.

[6] Brown, H. Douglas. Principles of Language Learning and Teaching. (San Francisco University, Pearson Longman, 2000).

[7] Çakir, I. A problem tense to teach: The present perfect. ELT Weekly, 3(80), 2011.

[8] Eid, A. The present tense between English and Arabic: A comparative study. Zarqa Private University, Amman, Jordan, 2006. Retrieved from http://www.scribd.com/doc/4616192/.

[9] Ellis, N. C. At the interface: How explicit knowledge affects implicit language learning. Studies in Second Language Acquisition, 27, 2005, 305-352.

[10] Fenner, A-B. Cultural Awareness and Language Awareness Based on Dialogic Interaction with Text in Foreign Language Learning. (Malta: Council Publishing, 2001).

[11] Franz, L. The Direct Method. 2004. Retrieved from http://www2.vobs.at/.../Alternative\%20methods/Direct\%20method.doc

[12] Fromkin, V., Rodman, R., \& Hyams, N. An Introduction to Language. (Boston: Thomson Wadsworth, 2007).

[13] Gardner, S. Changing approaches to teaching grammar. ELTED, 11, $2008 . \quad$ Retrieved from http://abisamra03.tripod.com/nada/languageacq-erroranalysis.html

[14] Jabak, O. Analysis of the most commonly recurring difficulties facing Arab students when translating into English. (Unpublished master dissertation). School of Languages, University of Salford, Salford, UK, 2007.

[15] Lado, R. Linguistics across Cultures: Applied Linguistics for Language Teachers. Michigan: University of Michigan, 1957.

[16] Ming-jun, Wu. Principal Approaches of Grammar Instruction. US-China Foreign Language, Volume 6, No.11 (Serial No.62), ISSN1539-8080, USA, 2008.

[17] Mohammed, A. Interlingual transfer in foreign language learning: A critical survey of the second half of the past century. The Educational Journal, 20, 77, 2004

[18] Prensky, Marc. The Motivation of Gameplay: The REAL 21st century learning revolution. On The Horizon, Volume 10 No 1, 2002.

[19] Rabab'ah, G. Communication problems facing Arab learners of English. Garzer Linguistische Studien 63, 2005.

[20] Swan, M. Practical English usage. (Hong Kong: Oxford University Press, 1982).

[21] VanPatten, B., Williams, J., \& Rott, S. Form-Meaning Connections in Second Language Acquisition. (Mahwah, NJ.: Lawrence Erlbaum, 2004).

[22] Vernon, S. A. Benefits of using games in the classroom. 2009. Retrieved from http://www.teachingenglishgames.com 